OPEN ACCESS

Edited by:

Zhongheng Zhang,

Sir Run Run Shaw Hospital, China

Reviewed by: Jesus Rico-Feijoo,

Hospital Universitario Río

Hortega, Spain

Massimiliano Sorbello,

Gaspare Rodolico Hospital, Italy

${ }^{*}$ Correspondence:

Cheng $\mathrm{Li}$

chengli_2017@tongji.edu.cn

Xuan Zhao

594079127@qq.com

†These authors have contributed equally to this work

Specialty section: This article was submitted to Intensive Care Medicine and

Anesthesiology,

a section of the journal

Frontiers in Medicine

Received: 17 July 2021 Accepted: 12 October 2021 Published: 16 November 2021

Citation:

Wang S, Hu C, Zhang T, Zhao X and

Li C (2021) Comparison of

Cricothyroid Membrane Puncture Anesthesia and Topical Anesthesia for Awake Fiberoptic Intubation: A

Double-Blinded Randomized

Controlled Trial.

Front. Med. 8:743009.

doi: 10.3389/fmed.2021.743009

\section{Comparison of Cricothyroid Membrane Puncture Anesthesia and Topical Anesthesia for Awake Fiberoptic Intubation: A Double-Blinded Randomized Controlled Trial}

\author{
Shaocheng Wang ${ }^{1,2,3 \dagger}$, Chaoli Hu ${ }^{3 \dagger}$, Tingting Zhang ${ }^{3}$, Xuan Zhao ${ }^{3 *}$ and Cheng $\mathrm{Li}^{2,3,4,5 *}$ \\ ${ }^{1}$ Department of Anesthesiology, Shanghai Pulmonary Hospital, School of Medicine, Tongji University, Shanghai, China, \\ ${ }^{2}$ Department of Anesthesiology and Perioperative Medicine, Shanghai Fourth People's Hospital, School of Medicine, Tongji \\ University, Shanghai, China, ${ }^{3}$ Department of Anesthesiology, Shanghai Tenth People's Hospital, School of Medicine, Tongji \\ University, Shanghai, China, ${ }^{4}$ Translational Research Institute of Brain and Brain-Like Intelligence, Shanghai Fourth People's \\ Hospital, School of Medicine, Tongji University, Shanghai, China, ${ }^{5}$ Clinical Research Center for Anesthesiology and \\ Perioperative Medicine, Tongji University, Shanghai, China
}

Background: Awake fiberoptic intubation (AFOI) is commonly used for patients with a difficult airway. The purpose of this study was to evaluate the efficacy of cricothyroid membrane puncture anesthesia and topical anesthesia during AFOI.

Methods: A total of 70 patients (the American Society of Anesthesiologists score I-III) with anticipated difficult airways scheduled for nonemergency surgery with AFOI were randomly slated to receive cricothyroid membrane puncture anesthesia $(n=35)$ or topical anesthesia $(n=35)$. Each group received dexmedetomidine at a dose of $1.0 \mu \mathrm{g} / \mathrm{kg}$ and sufentanil at a dose of $0.2 \mu \mathrm{g} / \mathrm{kg}$ over $10 \mathrm{~min}$ for conscious sedation before intubation. The endoscopy intubation, post-intubation condition, and endoscopy tolerance as scored by the anesthetists were observed. The satisfaction of the operator regarding the procedure and the satisfaction of the patient $24 \mathrm{~h}$ after the surgery were also recorded. We recorded the success rate of the first intubation, intubation time, and hemodynamic changes during the procedure and also the adverse events.

Results: Better intubation scores, operator satisfaction, and satisfaction of the patient were observed in the cricothyroid membrane puncture anesthesia group than in the topical anesthesia group $(p<0.05)$. The intubation time in the cricothyroid membrane puncture anesthesia group was less than that in the topical anesthesia group ( $p<$ 0.05). There were no significant differences in the patient tolerance scores, the success rate of the first intubation, hemodynamic changes, and adverse events between both the groups.

Conclusion: Compared with topical anesthesia, cricothyroid membrane puncture anesthesia provided better intubation conditions and less intubation time with greater satisfaction of the patient and operator during endoscopic intubation. 


\section{Clinical Trial Registration: URL: http://www.chictr.org.cn/showproj.aspx?proj=} 42636, Identifier: ChiCTR 1900025820.

Keywords: cricothyroid membrane puncture anesthesia, topical anesthesia, difficult airway, awake fiberoptic intubation (AFOI), dexmedetomidine (DEX), sufentanil

\section{INTRODUCTION}

The incidence of the difficult airway during clinical anesthesia is as high as $4.5-7.5 \%$ (1); this is a significant issue, as failure to maintain an unobstructed patient airway may lead to hypoxemia, brain damage, or even death (2). Awake fiberoptic intubation (AFOI) is an effective technique for the patients with difficult airways; it is considered the gold standard among intubation techniques $(3,4)$. Optimal intubation conditions for AFOI are as follows: the patient should be comfortable, cooperative, and have hemodynamic stability; moreover, the anesthesiologist must be able to maintain the airway of the patient with spontaneous ventilation (5). To achieve these conditions, adequate conscious sedation and high-grade local anesthesia are required. Previous studies have demonstrated that sufentanil and dexmedetomidine provide effective sedation during AFOI without depressing respiratory function (6-11).

The two most commonly used local anesthesia techniques are: cricothyroid membrane puncture anesthesia and topical anesthesia that can provide reasonable levels of safety and comfort (12-15). The duration of AFOI should be kept as short as possible to minimize the patient discomfort. Compared with the topical anesthesia performed by using the spray-as-you-go technique $(16,17)$, cricothyroid membrane puncture anesthesia seems to be faster and more effective (18-21). To the best of our knowledge, there is no previous study that has compared topical anesthesia and cricothyroid membrane puncture anesthesia in awake fiberoptic nasotracheal intubation. Therefore, this study was designed to compare the efficacy of the topical anesthesia and cricothyroid membrane puncture anesthesia in patients with difficult airway during AFOI.

\section{MATERIALS AND METHODS}

This study was approved by the Institutional Review Board of the Ethics Committee of Shanghai Tenth People's Hospital affiliated with the Shanghai Tongji University School of Medicine (SHSY-IEC-4.0/19-81-01). Written informed consent was obtained from each patient. It was registered as a clinical trial (www.chictr.org.cn, Identifier: ChiCTR 1900025820). We recruited 81 patients who were $18-80$ years old and scheduled for AFOI due to an anticipated difficult airway with an American Society of Anesthesiologists (ASA) score of I-III. The exclusion criteria included the heart rate $(\mathrm{HR})<50$ beats/min, systolic blood pressure (SBP) $<90 \mathrm{~mm} \mathrm{Hg}$, use of an $\alpha 2$-adrenoreceptor agonist or antagonist within the past 14 days, cirrhosis, nasal injury, nasal polyps, upper airway obstruction, skull base fracture, sinusitis, intracranial hypertension, heart failure, emergency surgery, coagulation disorders, contraindication to the performance of cricothyroid membrane puncture (thyroid swelling, local infection, or laryngeal disorder), allergic to related drugs and materials, cannot cooperate actively, and cannot objectively describe the symptoms. A total of 11 patients were excluded, seven patients met the exclusion criteria and four patients declined to participate. The remaining 70 patients were assigned (using a computer-generated randomization schedule) to receive topical anesthesia (Group A) or cricothyroid membrane puncture anesthesia (Group B). An anesthetist nurse generated the allocation sequence and assigned the patients to their groups, while another anesthetist nurse recorded the experimental and postoperative follow-up data. One anesthetist prepared the drug infusion, while another anesthetist was in charge of cricothyroid membrane puncture and intubation, graded intubation condition, and operator satisfaction. The patients, anesthetist nurses, and intubating anesthetist were all blinded to the group allocation.

Once the patient was transferred to the operation room, intravenous access was established and standard monitoring parameters (non-invasive blood pressure, pulse oximetry, and ECG) were recorded every $2 \mathrm{~min}$. The patient inhaled oxygen through a nasal catheter $(4 \mathrm{l} / \mathrm{min})$. Topical anesthesia of the nasal cavity was initiated using $2 \mathrm{ml} 2 \%$ lidocaine; simultaneously, $2 \mathrm{ml} 1 \%$ ephedrine was instilled into the nasal cavity to contract the nasal vessels. Sufentanil $(0.2 \mu \mathrm{g} / \mathrm{kg})$ and dexmedetomidine ( $1 \mu \mathrm{g} / \mathrm{kg}$ ) were diluted into $100 \mathrm{ml} 0.9 \%$ saline and the patient received the drugs intravenously over $10 \mathrm{~min}$. When drug infusion was completed, cricothyroid membrane puncture was performed by using a $23 \mathrm{G}$ needle. After verification of intratracheal placement by performing air aspiration, $3 \mathrm{ml}$ of $2 \%$ lidocaine was injected in Group B, while $3 \mathrm{ml}$ of $0.9 \%$ saline was injected in Group A. After injection, the patient was asked to cough to transport the local anesthetic from the tracheal injection site to the supraglottic mucosa. After a cricothyroid membrane puncture, a $30 \mathrm{sec}$ wait was conducted as part of the protocol. When cricothyroid membrane puncture was accomplished, a fiberoptic scope (Olympus LF-DP $3.1 \mathrm{~mm}$, Olympus, Tokyo, Japan) was loaded with a 7.0-mm tracheal tube for male patients or a $6.5-\mathrm{mm}$ tube for female patients. Then, $2 \mathrm{ml}$ of $2 \%$ lidocaine for Group A or $2 \mathrm{ml}$ of $0.9 \%$ saline for Group B was sprayed directly onto the glottis through the channel of the fiberoptic scope once the glottic structures were identified. After a 1-min wait, another $2 \mathrm{ml}$ of $2 \%$ lidocaine for Group A or $2 \mathrm{ml}$ of $0.9 \%$ saline for Group B was sprayed below the vocal cords. After a further 1-min wait, the tracheal tube was slightly inserted via the fiberoptic scope tube. During intubation, if the peripheral oxygen saturation $\left(\mathrm{SpO}_{2}\right)$ of the patient fell $\leq 92 \%$, the procedure was halted and the patient was asked to take deep breaths. Another intubation attempt was made when the $\mathrm{SpO}_{2}$ was recovered to $\geq 95 \%$. Hemodynamic changes ( $\mathrm{HR}$, mean arterial pressure, and pulse oximetry) were analyzed for both the groups 


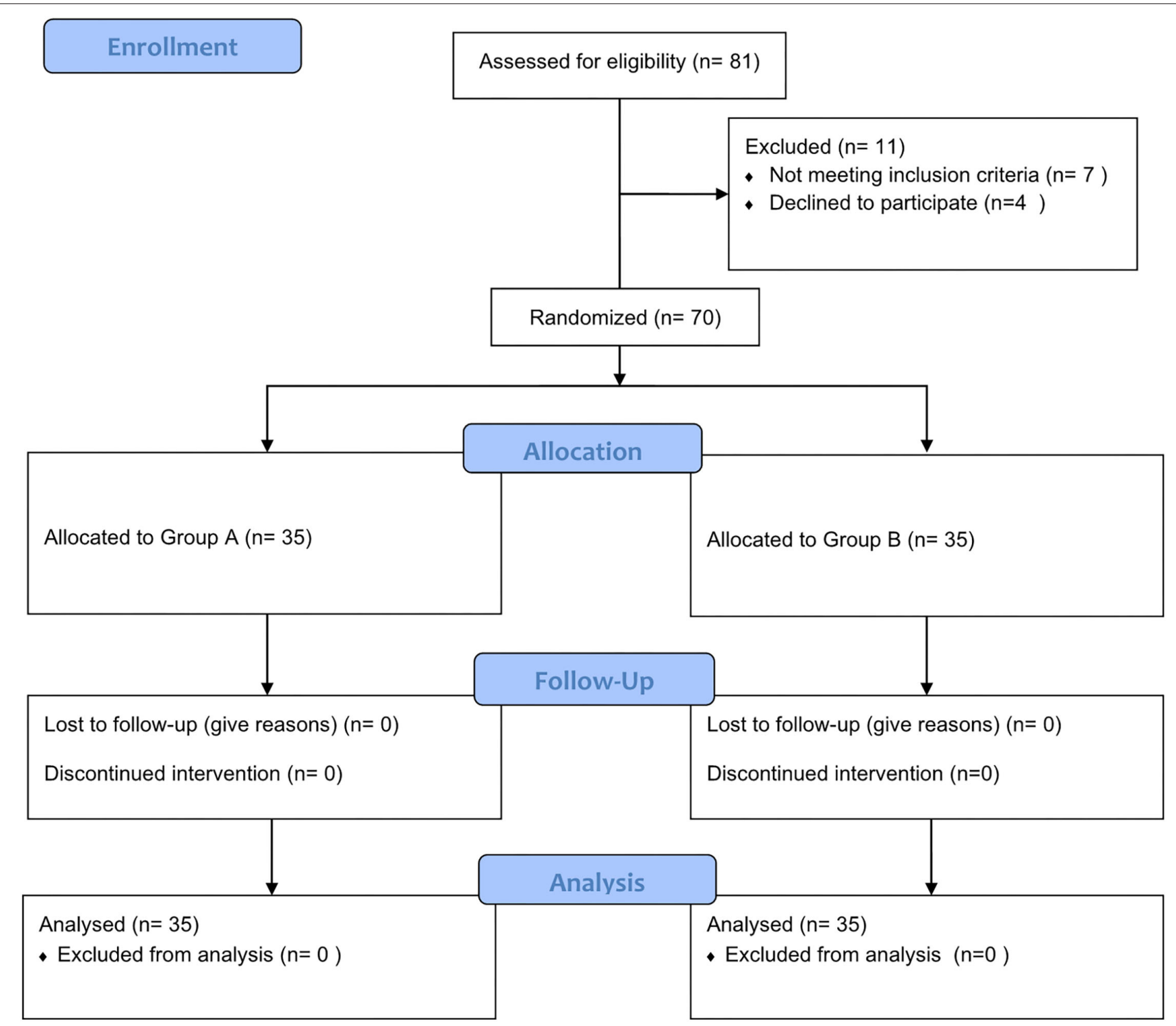

FIGURE 1 | Flowchart for the study recruitment.

at three time points (baseline, immediately after drug infusion, and immediately after intubation).

The primary outcomes included intubation times (from the begging of cricothyroid membrane puncture to the end of nasal tracheal intubation); intubation scores as assessed according to the vocal cord movement (1, open; 2, moving; 3, closing; 4, closed), coughing (1, none; 2 , slight; 3 , moderate; 4 , severe), and limb movement (1, none; 2 , slight; 3 , moderate; 4 , severe); patient tolerance as assessed using a five-point fiberoptic intubation comfort score (1, no reaction; 2, slight grimacing; 3 , heavy grimacing; 4, verbal objection; 5 , defensive movement of head or hands), and a three-point score assessed immediately after nasotracheal intubation (1, cooperative; 2 , minimal resistance; 3 , severe resistance); and first intubation attempt success rate.

Other parameters during intubation included the satisfaction of the operator regarding the intubation process $(0$, completely dissatisfied; 10, completely satisfied) and the occurrence of a hypoxic episode $\left(\mathrm{SpO}_{2}<92 \%\right)$. All the adverse events were recorded.

\section{STATISTICAL ANALYSIS}

We used the GraphPad Prism version 8.0 (GraphPad Software Inc., San Diego, California, USA) for the statistical analyses. Continuous variables are described as mean \pm SD and were compared by using the paired $t$-test. The chi-squared test or the Fisher's exact test was used to compare categorical variables between the groups. Intubation conditions and tolerance score were analyzed using the independent samples Mann-Whitney $U$ test. Blood pressure and HR at different time points were compared by using the two-way repeated measures analysis of variance. A $p<0.05$ was regarded as statistically significant. 


\section{RESULTS}

A total of 70 patients (33 males and 37 females) with anticipated difficult airways were enrolled in this study (Figure 1). The baseline data of the two groups showed no differences (Table 1).

The Ramsay Sedation Scale (RSS) score after the drug infusion showed no significant differences between both the groups. All

TABLE 1 | Demographic and clinical characteristics of study participants.

\begin{tabular}{lccc}
\hline Characteristic & $\begin{array}{c}\text { Group A } \\
(\boldsymbol{n}=\mathbf{3 5})\end{array}$ & $\begin{array}{c}\text { Group B } \\
(\boldsymbol{n}=\mathbf{3 5})\end{array}$ & $\boldsymbol{P}$ value \\
\hline Age (years) & $57.6 \pm 9.8$ & $56.7 \pm 11.9$ & 0.734 \\
Sex (male/female) & $16 / 19$ & $17 / 18$ & 0.811 \\
Weight (Kg) & $66.2 \pm 9.8$ & $65.2 \pm 10.1$ & 0.657 \\
ASA status (1/2/3) & $16 / 16 / 3$ & $12 / 20 / 3$ & 0.602 \\
Mallampatti grade (2/3/4) & $6 / 19 / 10$ & $8 / 20 / 7$ & 0.841 \\
Mouth opening (cm) & $3.6 \pm 0.6$ & $3.8 \pm 0.7$ & 0.184 \\
RSS score (1/2) & $8 / 27$ & $6 / 29$ & 0.766 \\
\hline
\end{tabular}

Data are presented as mean \pm standard (SD) or number.

ASA, American Society of Anesthesiologists.

TABLE 2 | Airway management characteristics.

\begin{tabular}{lccc}
\hline & $\begin{array}{c}\text { Group A } \\
(\boldsymbol{n}=\mathbf{3 5})\end{array}$ & $\begin{array}{c}\text { Group B } \\
(\boldsymbol{n}=\mathbf{3 5})\end{array}$ & $\boldsymbol{P}$ value \\
\hline RSS after drug infusion (2/3) & $9 / 26$ & $12 / 23$ & 0.603 \\
First intubation attempt success rate & 94.286 & 100 & 0.151 \\
(\%) & & & \\
Intubation time (sec) & $244.1 \pm 91.5$ & $200.4 \pm 28.1$ & 0.003 \\
Intubation scores & & & 0.01 \\
Vocal cord movement 1/2/3/4 & $12 / 17 / 4 / 0$ & $22 / 12 / 1 / 0$ & 0.002 \\
Cough 1/2/3/4 & $14 / 18 / 3 / 0$ & $27 / 8 / 0 / 0$ & 0.002 \\
Limb movement 1/2/3/4 & $22 / 6 / 7 / 0$ & $29 / 5 / 1 / 0$ & 0.29 \\
Patient tolerance 1/2/3/4 & $10 / 20 / 5 / 0$ & $17 / 17 / 1 / 0$ & 0.267 \\
Patients' comfort score after & $24 / 10 / 1 / 0$ & $30 / 4 / 1 / 0$ & \\
intubation 1/2/3/4 & & & 0.0001 \\
Operator's satisfaction (1-10) & $7 \pm 0.5$ & $8.9 \pm 0.9$ & \\
\hline
\end{tabular}

Data are presented as mean \pm standard (SD) or number.

RSS, Ramsay sedation score. the patients were successfully intubated with AFOI. There was no significant difference between both groups in the first intubation attempt success rate, but the first intubation attempt failed in two patients from Group A. The intubation time in Group B (200.4 \pm $28.1)$ was lower than in Group A $(244.1 \pm 91.5)(p=0.003)$. The intubation scores were better in Group B compared with Group A with regard to the vocal cord movement, cough, limb movement, and operator satisfaction $(p<0.05)$, but there was no significant difference in the patient tolerance score and comfort score of the patients after intubation (Table 2).

There was no significant difference in the hemodynamic change between both the groups at three time points: baseline, immediately after drug infusion, and immediately after intubation (Figure 2).

The incidence of adverse events (hypertension, hypotension, tachycardia, bradycardia, and hypoxia) was not significantly different between both the groups. Postanesthetic interview parameters: hoarseness, sore throat, and recall of intubation did not differ between both the groups, but patient satisfaction in Group B $(9.4 \pm 0.8)$ was better compared with that in Group A $(7.5 \pm 1.3)(p=0.0007)$ (Table 3).

\section{DISCUSSION}

This study aimed to compare the two techniques of topical anesthesia that are both deemed effective during AFOI in patients with anticipated difficult airways. To the best of our knowledge, our study is the first to compare cricothyroid membrane puncture anesthesia and topical anesthesia in awake fiberoptic nasotracheal intubation.

In the existing literature on AFOI, several viewpoints exist. Some studies mention that cricothyroid membrane puncture anesthesia is a more effective method than topical anesthesia using the spray-as-you-go technique $(18,22)$, while others state that the spray-as-you-go technique is superior to the cricothyroid membrane puncture technique (23).

This study showed that both the cricothyroid membrane puncture anesthesia and topical anesthesia were effective for AFOI, but the cricothyroid membrane puncture anesthesia technique required less intubation time and led to better intubation scores, a higher success rate of first intubation,
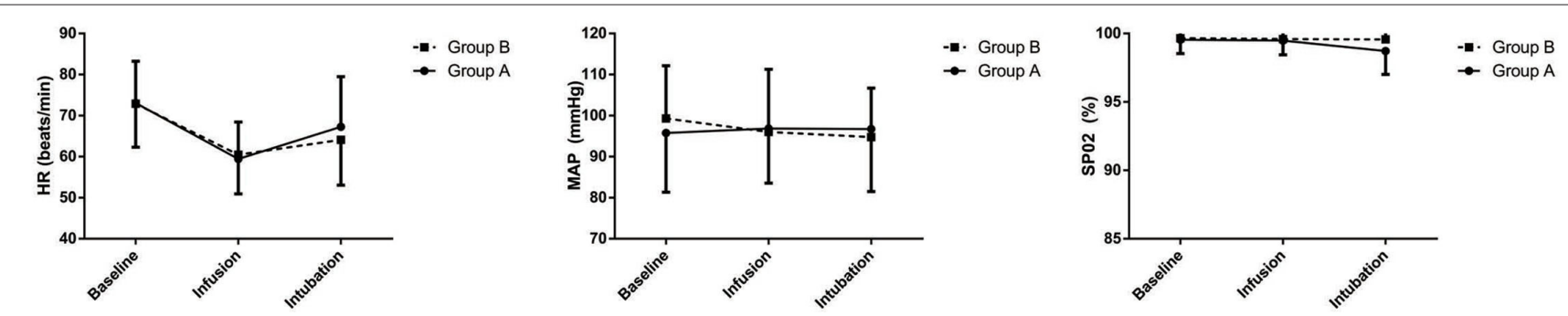

FIGURE 2 | Heart rate (HR), mean arterial blood pressure (MAP), and peripheral oxygen saturation (SpO $\mathrm{S}_{2}$ ) before premedication (baseline), immediately after drug infusion (infusion), and immediately after intubation (intubation). Group A: Topical anesthesia; Group B: Cricothyroid membrane puncture anesthesia. Points are expressed as mean $\pm \mathrm{SD}$. 
TABLE 3 | Postoperative visit data and advent events.

\begin{tabular}{lccc}
\hline & $\begin{array}{c}\text { Group A } \\
(\boldsymbol{n}=\mathbf{3 5})\end{array}$ & $\begin{array}{c}\text { Group B } \\
(\boldsymbol{n}=\mathbf{3 5})\end{array}$ & $\boldsymbol{P}$ value \\
\hline Hoarseness & 1 & 1 & 1 \\
Sore throat & 1 & 3 & 0.614 \\
Recall of intubation & 25 & 30 & 0.244 \\
Patients' satisfaction & $7.5 \pm 1.3$ & $9.4 \pm 0.8$ & 0.0007 \\
Hypertension & 0 & 0 & 1 \\
hypotension & 0 & 0 & 1 \\
tachycardia & 1 & 1 & 1 \\
bradycardia & 2 & 3 & 0.69 \\
hypoxia & 0 & 0 & 1 \\
\hline
\end{tabular}

Data are presented as mean \pm standard (SD) or number.

and a higher satisfaction score for both operator and patients during AFOI.

We chose the intubation time as the primary outcome of our study, because it is the clearest criterion to evaluate the efficiency of AFOI. Along with an adequate analgesia and sedation, we believe that a rapid AFOI procedure is important for ensuring safety and comfort of the patient. Our study found that the cricothyroid membrane puncture anesthesia technique was significantly faster than the topical anesthesia technique; this is consistent with the results of a previous study (24). Moreover, to ensure the double blindness of the experiment, the cricothyroid membrane puncture anesthesia group also used the spray-asyou-go technique for comparison with topical anesthesia; this increased the intubation time by $2 \mathrm{~min}$ and might have reduced patient comfort and satisfaction.

The secondary outcomes were the intubation scores during AFOI. Scoring systems similar to the one we used to evaluate intubation scores are described in the literature $(6,25,26)$, but the results were different in those studies. Our study showed that the cricothyroid membrane puncture anesthesia technique was better than the topical anesthesia technique as it exhibited better intubation scores, higher success rate of first intubation, and higher operator satisfaction score. Although cricothyroid membrane puncture anesthesia was administered subglottically, it provided a better topical block. Despite the fact that the patient tolerance and patient comfort scores were better in the cricothyroid membrane puncture anesthesia group, this difference did not achieve statistical significance.

We knew from our experience and from the literature (2729) that adequate analgesia and sedation are necessary for AFOI. Therefore, we administered sufentanil $(0.2 \mu \mathrm{g} / \mathrm{kg})$ and dexmedetomidine $(1 \mu \mathrm{g} / \mathrm{kg})$ over $10 \mathrm{~min}$ before AFOI to obtain sufficient analgesia and sedation. On following this procedure, all the patients had an RSS score $>1$ after the drug infusion and no patient felt obvious pain in any of the AFOI procedures; this result is consistent with those of the previous studies (30-32).

Hemodynamic stability is a measure of stress response during AFOI. We did not find any significant difference between the two groups regarding this factor. This finding is consistent with the results of the previous studies, wherein AFOI performed by experienced operators had no influence on the hemodynamic stability of the patient $(33,34)$.

Dexmedetomidine has been reported to decrease noradrenaline release and centrally mediated sympathetic tone (35). However, it may cause side effects including hypotension, bradycardia, and hypoxia (36). In our study, five patients developed bradycardia after drug infusion that can be treated easily with atropine and two patients developed tachycardia after intubation. There was no significant difference between the two groups regarding the adverse effects of dexmedetomidine.

Postoperative visit data showed the majority of the patients had no hoarseness or soreness of the throat. The cricothyroid membrane puncture anesthesia group exhibited higher patient satisfaction and less recall of intubation than the topical anesthesia group. Therefore, we conclude that cricothyroid membrane puncture anesthesia technique, if performed by experienced anesthesiologists, provide a high level of comfort to the patient.

This study had some limitations. There were only 70 patients enrolled in our study, further larger sample studies are required to confirm our results. Another limitation was the lack of dose-effect study; the doses of sufentanil and dexmedetomidine used were based on data provided in the previous studies. Our drug infusion protocol is not suitable for the emergency operation, as it requires more than $10 \mathrm{~min}$. Despite sufficient analgesia and sedation, cricothyroid membrane puncture is still an invasive operation.

\section{CONCLUSION}

Both the techniques of topical anesthesia are effective in AFOI, but cricothyroid membrane puncture anesthesia provided better intubation conditions and less intubation time with greater satisfaction of the patient and operator when compared with topical anesthesia.

\section{DATA AVAILABILITY STATEMENT}

The original contributions presented in the study are included in the article/supplementary material, further inquiries can be directed to the corresponding author/s.

\section{ETHICS STATEMENT}

The studies involving human participants were reviewed and approved by Review Board of the Ethics Committee of Shanghai Tenth People's Hospital affiliated with Shanghai Tongji University School of Medicine (SHSYIEC-4.0/19-81-01). The patients/participants provided their written informed consent to participate in this study.

\section{AUTHOR CONTRIBUTIONS}

SW, CH, TZ, XZ, and CL: provision of study materials or patients, collection and assembly of data, and final 
approval of manuscript. CL: administrative support. SW, $\mathrm{CH}, \mathrm{XZ}$, and $\mathrm{CL}$ : conception and design, data analysis and interpretation, and manuscript writing. All authors contributed to the article and approved the submitted version.

\section{FUNDING}

This study was supported by the National Natural Science Foundation of China (Grant Number 81600921) located in No. 83 Shuangqing Road, Haidian District, Beijing, 100085, China

\section{REFERENCES}

1. Shiga $T$, Wajima $Z$, Inoue $T$, Sakamoto A. Predicting difficult intubation in apparently normal patients: a meta-analysis of bedside screening test performance. Anesthesiology. (2005) 103:429-37. doi: 10.1097/00000542-200508000-00027

2. Schmitt $H$, Buchfelder $M$, Radespiel-Tröger $M$, Fahlbusch R. Difficult intubation in acromegalic patients: incidence and predictability. Anesthesiology. (2000) 93:110-4. doi: 10.1097/00000542-200007000-00020

3. Wang S, Hu C, Zhang T, Zhao X, Li C. Practice guidelines for management of the difficult airway: an updated report by the American Society of anesthesiologists task force on management of the difficult airway. Anesthesiology. (2003) 98:1269-77. doi: 10.1097/00000542-200305000-00032

4. Apfelbaum JL, Hagberg CA, Caplan RA. Practice guidelines for management of the difficult airway: an updated report by the American Society of anesthesiologists task force on management of the difficult airway. Anesthesiology. (2013) 118:251-70. doi: 10.1097/ALN.0b013e31827773b2

5. Dang BW, Zhang J. Safety and efficacy of argon plasma coagulation for resection of lipomas and hamartomas in large airways. Asian Pacific J Cancer Prevent. APJCP. (2011) 12:477-80. doi: 10.1097/01.cad.0000390767.85658.83

6. Li CW Li YD, Tian HT, Kong XG, Chen K. Dexmedetomidine-midazolam versus Sufentanil-midazolam for awake fiberoptic nasotracheal intubation: a randomized double-blind study. Chin Med J. (2015) 128:3143-8. doi: 10.4103/0366-6999.170260

7. Chu KS, Wang FY, Hsu HT, Lu IC, Wang HM, Tsai CJ. The effectiveness of dexmedetomidine infusion for sedating oral cancer patients undergoing awake fibreoptic nasal intubation. Eur J Anaesthesiol. (2010) 27:36-40. doi: 10.1097/EJA.0b013e32832e0d2b

8. Shen SL, Xie YH, Wang WY, Hu SF, Zhang YL. Comparison of dexmedetomidine and sufentanil for conscious sedation in patients undergoing awake fibreoptic nasotracheal intubation: a prospective, randomised and controlled clinical trial. Clin Respir J. (2014) 8:100-7. doi: $10.1111 /$ crj. 12045

9. Bergese SD, Patrick Bender S, McSweeney TD, Fernandez S, Dzwonczyk R, Sage $\mathrm{K}$, et al. comparative study of dexmedetomidine with midazolam and midazolam alone for sedation during elective awake fiberoptic intubation. $J$ Clin Anesth. (2010) 22:35-40. doi: 10.1016/j.jclinane.2009.02.016

10. Stamenkovic DM, Hassid M. Dexmedetomidine for fiberoptic intubation of a patient with severe mental retardation and atlantoaxial instability. Acta Anaesthesiol Scand. (2006) 50:1314-5. doi: 10.1111/j.1399-6576.2006.01157.x

11. Maroof M, Khan RM, Jain D, Ashraf M. Dexmedetomidine is a useful adjunct for awake intubation. Canad J Anaesthesia. (2005) 52:776-7. doi: 10.1007/BF03016576

12. Isaac PA, Barry JE, Vaughan RS, Rosen M, Newcombe RG, A. jet nebuliser for delivery of topical anesthesia to the respiratory tract. a comparison with cricothyroid puncture and direct spraying for fibreoptic bronchoscopy. Anaesthesia. (1990) 45:46-8. doi: 10.1111/j.1365-2044.1990.tb14504.x

13. Koerner IP, Brambrink AM. Fiberoptic techniques. Best practice and research. Clinic Anaesthesiol. (2005) 19:611-21. doi: 10.1016/j.bpa.2005.07.006

14. Andruszkiewicz P, Dec M, Kański A, Becler R. Awake fibreoptic intubation. Anestezjologia intensywna terapia. (2010) 42:218-21. and the Natural Science Foundation of Shanghai (Grant Number 20ZR1442900) located in No. 200, Renmin Avenue, Shanghai, 200003, China.

\section{ACKNOWLEDGMENTS}

We sincerely thank the Department of Anesthesiology, Shanghai Tenth People's Hospital, Tongji University School of Medicine, Shanghai, 200072, China. The Department of Anesthesiology provided all the medical apparatus and instruments for this study.
15. Andruszkiewicz P, Dec M, Kański A, Becler R. Fibreoptic intubation in awake patients. Anestezjologia intensywna terapia. (2010) 42(4):194-196.

16. Pirlich N, Lohse JA, Noppens RR. Topical airway anesthesia for awakeendoscopic intubation using the spray-as-you-go technique with high oxygen flow. JoVE. (2017) 13:119. doi: 10.3791/55116

17. Sidhu VS, Whitehead EM, Ainsworth QP, Smith M, Calder I, A. technique of awake fibreoptic intubation. experience in patients with cervical spine disease. Anaesthesia. (1993) 48:910-3. doi: 10.1111/j.1365-2044.1993.tb07429.x

18. Webb AR, Fernando SS, Dalton HR, Arrowsmith JE, Woodhead MA, Cummin AR. Local anaesthesia for fibreoptic bronchoscopy: transcricoid injection or the "spray as you go" technique? Thorax. (1990) 45:474-7. doi: 10.1136/thx.45.6.474

19. Peiris K, Frerk C. Awake intubation. J Perioper Pract. (2008) 18:96-104. doi: $10.1177 / 175045890801800302$

20. Madan K, Mittal S, Gupta N, Biswal SK, Tiwari P, Hadda V, et al. The Cricothyroid versus spray-as-you-go method for topical anesthesia during flexible bronchoscopy: the crisp randomized clinical trial. Respirat Int Rev Thorac Dis. (2019) 98:440-46. doi: 10.1159/000501563

21. Chandra A, Banavaliker JN, Agarwal MK. Fibreoptic bronchoscopy without sedation: is transcricoid injection better than the "spray as you go" technique? Indian J Anaesth. (2011) 55:483-7. doi: 10.4103/0019-5049. 89877

22. Graham DR, Hay JG, Clague J, Nisar M, Earis JE. Comparison of three different methods used to achieve local anesthesia for fiberoptic bronchoscopy. Chest. (1992) 102:704-7. doi: 10.1378/chest.102.3.704

23. Sethi N, Tarneja VK, Madhusudanan TP, Shouche S. Local anaesthesia for fiberoptic intubation: a comparison of three techniques. Med J Armed Forces India. (2005) 61:22-5. doi: 10.1016/S0377-1237(05)80112-1

24. Malcharek MJ, Bartz M, Rogos B, Günther L, Sablotzki A, Gille J, et al. Comparison of Enk Fibreoptic Atomizer with translaryngeal injection for topical anaesthesia for awake fibreoptic intubation in patients at risk of secondary cervical injury: a randomised controlled trial. Eur J Anaesthesiol. (2015) 32:615-23. doi: 10.1097/EJA.0000000000000285

25. Xu T, Li M, Ni C, Guo XY. Dexmedetomidine versus remifentanil for sedation during awake intubation using a Shikani optical stylet: a randomized, double-blinded, controlled trial. BMC Anesthesiol. (2016) 16:52. doi: 10.1186/s12871-016-0219-9

26. Hu R, Liu JX, Jiang H. Dexmedetomidine versus remifentanil sedation during awake fiberoptic nasotracheal intubation: a double-blinded randomized controlled trial. J Anesth. (2013) 27:211-7. doi: 10.1007/s00540-012-1499-y

27. Liu HH, Zhou T, Wei JQ, Ma WH. Comparison between remifentanil and dexmedetomidine for sedation during modified awake fiberoptic intubation. Exp Ther Med. (2015) 9:1259-64. doi: 10.3892/etm.2015.2288

28. Lallo A, Billard V, Bourgain JL, A. comparison of propofol and remifentanil target-controlled infusions to facilitate fiberoptic nasotracheal intubation. Anesth Analg. (2009) 108:852-7. doi: 10.1213/ane.0b013e318184eb31

29. Machata AM, Gonano C, Holzer A, Andel D, Spiss CK, Zimpfer $\mathrm{M}$, et al. Awake nasotracheal fiberoptic intubation: patient comfort, intubating conditions, and hemodynamic stability during conscious sedation with remifentanil. Anesth Analg. (2003) 97:904-8. doi: 10.1213/01.ANE.0000074089.39416.F1 
30. Wang JC, Yang TS, Chen PH, Huang WH, Hsiao SY, Wong CS, et al. Enhanced perioperative safety and comfort during airway-related surgeries and procedures with dexmedetomidine-a brief review and clinical practice experience. Asian J Anesthesiol. (2018) 56:56-63. doi: 10.6859/aja.201806_56(2).0003

31. Mirkheshti A, Memary E, Honar BN, Jalaeefar A, Sezari P. The efficacy of local dexmedetomidine during fiberoptic nasotracheal intubation: A randomized clinical trial. J Anaesthesiol Clin Pharmacol. (2017) 33:209-14. doi: 10.4103/joacp.JOACP_242_16

32. Wang HL, Tang SH, Wang XQ, Gong WH, Liu XM, Lei WF. Doxapram hastens the recovery following total intravenous anesthesia with dexmedetomidine, propofol and remifentanil. Exp Ther Med. (2015) 9:1518-22. doi: 10.3892/etm.2015.2249

33. Piepho T, Thierbach AR, Gobler SM, Maybauer MO, Werner C. Comparison of two different techniques of fibreoptic intubation. Eur J Anaesthesiol. (2009) 26:328-32. doi: 10.1097/EJA.0b013e32831ac4ce

34. Sutherland AD, Williams RT. Cardiovascular responses and lidocaine absorption in fiberoptic-assisted awake intubation. Anesth Analg. (1986) 65:389-91. doi: 10.1213/00000539-198604000-00016

35. Bloor BC, Ward DS, Belleville JP, Maze M. Effects of intravenous dexmedetomidine in humans. ii hemodynamic changes. Anesthesiology. (1992) 77:1134-42. doi: 10.1097/00000542-199212000-00014
36. Ebert TJ, Hall JE, Barney JA, Uhrich TD, Colinco MD. The effects of increasing plasma concentrations of dexmedetomidine in humans. Anesthesiology. (2000) 93:382-94. doi: 10.1097/00000542-200008000-00016

Conflict of Interest: The authors declare that the research was conducted in the absence of any commercial or financial relationships that could be construed as a potential conflict of interest.

Publisher's Note: All claims expressed in this article are solely those of the authors and do not necessarily represent those of their affiliated organizations, or those of the publisher, the editors and the reviewers. Any product that may be evaluated in this article, or claim that may be made by its manufacturer, is not guaranteed or endorsed by the publisher.

Copyright (c) 2021 Wang, Hu, Zhang, Zhao and Li. This is an open-access article distributed under the terms of the Creative Commons Attribution License (CC BY). The use, distribution or reproduction in other forums is permitted, provided the original author(s) and the copyright owner(s) are credited and that the original publication in this journal is cited, in accordance with accepted academic practice. No use, distribution or reproduction is permitted which does not comply with these terms. 